\title{
MITOS DE FUNDAÇÃO DE TRÊS CIDADES BRASILEIRAS: TRÊS SANTOS, DOIS MASSACRES E UM COICE DE BURRO
}

Ailton Pereira Morila ${ }^{1}$

Resumo: O objetivo deste artigo é apresentar e analisar alguns mitos de fundação de três cidades brasileiras: São Paulo e São Carlos no estado de São Paulo e São Mateus, no estado do Espírito Santo. A análise documental de obras de história escritas por autores locais sem uma formação específica em história permite vislumbrar estes mitos que estão presentes nas comemorações oficiais e documentos de divulgação das cidades e são muitas vezes reproduzidos pela historiografia regional posterior, perpetuando-os. Nestes mitos encontramos valores e normas que se querem inculcar. Encontramos também sujeitos "esquecidos" ou "quase esquecidos" que quando muito aparecem em crônicas, apartados da história.

Palavras-chave: historiografia regional; mitos de fundação; São Paulo (SP); São Carlos (SP); São Mateus (ES).

\section{FOUNDATION MYTHS OF THREE BRAZILIAN CITIES: THREE SAINTS, TWO MASSACRES AND A DONKEY KICK}

\begin{abstract}
The purpose of this article is to present and analyze some foundation myths of three Brazilian cities: São Paulo and São Carlos in São Paulo state and São Mateus, in the state of Espirito Santo. The historical books documental analysis built by local authors without academical history education allows to glimpse these myths are present in the official celebrations and disclosure documents of cities and are often reproduced by subsequent regional historiography, perpetuating them. In the analysis of these myths we find values and norms that want to inculcate. We also found subjects "forgotten" or "almost forgotten" just appear in chronicles, apart from the history.
\end{abstract}

Keywords: Regional historiography; Foundation myths; São Paulo (SP); São Carlos (SP); São Mateus (ES).

\section{MITOS DE FUNDACIÓN DE TRES CIUDADES BRASILEÑAS: TRES SANTOS, DOS MASAJES Y UN COJE DE BURRO}

Resumen: El objetivo de este artículo es presentar y analizar algunos mitos de fundación de tres ciudades brasileñas: São Paulo y São Carlos en el estado de São Paulo y San Mateo, en el estado de Espírito Santo. El análisis documental de obras de historia escritas por autores locales sin una formación específica en historia permite vislumbrar estos mitos que están presentes en las conmemoraciones oficiales y documentos de divulgación de las ciudades y son muchas veces reproducidos por la historiografía regional posterior, perpetuándolos. En

\footnotetext{
${ }^{1}$ Doutor em Educação pela Faculdade de Educação da Universidade de São Paulo (USP). Professor Associado da Universidade Federal do Espírito Santo (UFES). Docente do Programa de Pós-Graduação em Ensino na Educação Básica da UFES.
} 
estos mitos encontramos valores y normas que se quieren inculcar. Encontramos también sujetos "olvidados" o "casi olvidados" que cuando muy aparecen en crónicas, apartados de la historia.

Palabras clave: historiografía regional; mitos de fundación; Sao Paulo (SP); San Carlos (SP); San Mateo (ES).

\section{INTRODUÇÃO}

Muita história foi escrita desde a clássica obra de historiografia brasileira, a Teoria da História no Brasil de José Honório Rodrigues, de 1949. Desde então a historiografia vem crescendo. Não só o conjunto das obras históricas, o primeiro sentido de historiografia atribuído por Arruda e Tengarrinha (1999, p 11), mas e principalmente a "reflexão [...] sobre o conhecimento histórico, ou seja, a reflexão sobre a produção dos historiadores ou, em termos correntes, sobre as obras históricas."

O presente artigo se inscreve na discussão historiográfica regional, analisando obras de autores locais sem uma formação específica em história, mas que são pioneiros na escrita da história de suas cidades. Na falta de uma historiografia acadêmica estes autores são o único referencial para a história das cidades nas comemorações e sítios oficiais e ainda na educação básica. Mesmo em cidades onde a historiografia acadêmica se faz presente algumas destas leituras permanecem. O recorte temporal escolhido é a fundação destas cidades no intuito de compreender as narrativas oficiais

A leitura destes autores inquieta em pelo menos duas coisas, objeto deste artigo. Embora publicadas em tempos distintos, as primeiras histórias escritas dos três municípios têm um estilo ou uma tônica similar umas às outras. Outra questão é o que poderíamos chamar de "mito de fundação" da cidade, perpetuado até os dias atuais em cada uma das cidades.

Mito, segundo Ferreira (2004) não é somente uma "ideia falsa" mas também uma "Narrativa de significação simbólica, transmitida de geração em geração dentro de determinado grupo, e considerada verdadeira por ele". Mas mais que isso os mitos e as lendas heroicas, segundo Jaeger (1994, p. 68) “constituem um tesouro inesgotável de exemplos e modelos da nação, que neles bebe o seu pensamento, ideais e normas para a vida". 
A primeira cidade analisada é São Paulo, principalmente os clássicos de sua fundação: Afonso Taunay (2016), engenheiro de formação atuou como Diretor do Museu Paulista, nos Instituto Histórico e Geográfico de São Paulo e Instituto Histórico e Geográfico Brasileiro e Aureliano Leite (1944), advogado de profissão.

O interior de São Paulo, mais especificamente os chamados "sertões de Araraquara" é o local da segunda cidade, São Carlos. Destacam-se os autores Botelho Ferraz (1957) e Camargo (1957).

Distante está São Mateus, uma cidade do norte do Espírito Santo, considerada por seus moradores como uma "das cidades mais antigas do país". A obra dos autores Nardoto e Lima (2001) é o marco desta história.

Este artigo traz algumas reflexões sobre estas duas questões envolvendo estas três cidades.

\section{TRÊS POVOADOS}

O povoado do Cricaré encontra-se no norte do Espírito Santo. Segundo as comemorações oficiais, a cidade é uma das mais antigas do Brasil. Dataria de 1544 sua fundação. A categoria de Vila só foi alcançada em 1764 (NARDOTO; LIMA, 2001).

Logo no inicio do povoamento um episódio teria sido marcante: a batalha do Cricaré. Vasco Fernandes Coutinho, donatário da capitania do Espírito Santo, teria deixado a cargo de Jorge de Menezes a administração da capitania. Ele, e seu sucessor, Simão de Castelo Branco, morreram em confronto com os índios. Na chegada de Vasco Fernandes Coutinho ao Brasil este pediu ao Governador Geral Mem de Sá auxílio contra os índios. Seis velas e duzentos homens foram cedidos para a empreitada. Estes homens, comandados por Fernão de Sá e secundado por Diogo de Morim Soares e Paulo Dias Adorno foram recebidos pelos índios com paliçadas. Segundo Nardoto (2001, p. 31-31), após intensas batalhas onde abundaram mortos de ambos os lados:

O capitão Fernão de Sá, filho do Governador Geral Mém de Sá, morreu com outros cinquenta homens, enquanto os outros cinco salvaram-se a nado. Essa batalha aconteceu próximo à confluência dos rios Cricaré e Mariricu, em 1558, fixando São Mateus na História do Brasil como o local em que os portugueses sofreram sua primeira derrota. 
Mitos de fundação de três cidades brasileiras: três santos, dois massacres e um coice de burro Ailton Pereira Morila

Após algumas derrotas marcantes, os portugueses enfim "pacificaram" a região ainda em 1558. (NARDOTO; LIMA, 2001). Esta pacificação, entretanto, parece não ter sido suficiente. Segundo Nardoto e Lima (2001, p. 107):

O progresso político-econômico alcançado em São Mateus, a partir da sua elevação a vila, favoreceu a vida sócio-cultural dos seus colonizadores. Continuavam, no entanto, os índios aimorés, ou botocudos, a atacarem as fazendas e destruírem toda espécie de melhoria que fosse feita por colonos em terras indígenas ou pelas redondezas. As expedições de novos colonos chegados da Europa, ou vindos de outras Províncias do Brasil, esbarravam à entrada das florestas, porque os botocudos não lhes permitiam explorações, atacando pessoas ou destruindo as construções, com estratégias sempre surpreendentes. Os botocudos sempre foram temidos e enfrentaram a ocupação branca, defendendo suas famílias e suas terras do norte do Espírito Santo nas matas dos rios São Mateus, Cotaxé e Doce.

A história que se conta dos botocudos enaltece os crimes contra eles praticados pelo branco invasor de suas terras. A valentia de suas defesas sempre foi propagada como crueldade, barbarismo e antropofagia.

Diferentemente da "batalha do Cricaré", ao longo de todo o século XIX e inicio do século XX, os índios foram sendo dizimados na região. Emboscadas, assassinatos de lideres, estupro de mulheres e crianças marcou todo o século XIX. Até mesmo a "doação" de roupas contaminadas com sarampo foi utilizada nesta guerra. O último ataque dos aimorés data de 1909.

Nos planalto de Piratininga, a história aponta também um massacre, ou quase. Em 1562 a pequena vila foi alvo de uma emboscada por parte dos indígenas. Leite (1944, p. 15) assim explica:

A guerra dos selvícolas contra os núcleos de portugueses e mamelucos, aos quais se tenta arrebatar as suas mulheres brancas (algumas foram levadas) e os seus escravos, culmina com o assédio fracassado contra a vila de SãoPaulo, aos 10 de Julho de 1562. Distingue-se na defeza de São-Paulo, o Príncipe Tibiriçá, que, pelo Natal, falece em consequência dos ferimentos recebidos.

Aureliano Leite (1944, p. 15) não deixa de exaltar a figura de do grande herói:

Tibiriçá expira na sua choupana do largo de São-Bento e é sepultado, primeiro, na igreja dos jesuítas, removido daí, quando da demolição do templo, para a igreja do Coração de Maria, e dali, finalmente, aos 1923, para a cripta da Catedral. [...] Tibiriçá, patriarca indígena dos paulistas, pertencia ao quadro dos cavaleiros da Ordem de Cristo, com tença anual concedida pelo governo português. 
De maneira similar, Taunay (2016) em a História da Cidade de São Paulo afirma:

Terrível o embate, repelido graças à bravura dos assaltados, a quem comandavam João Ramalho e Tibiriçá e certamente à superioridade embora ainda não muito considerável, na época, das armas de fogo de tiro muito lento e pequeno raio de alcance.

Contra si tinham os sitiados a grande inferioridade do número de combatentes. Rechaçados os sitiantes com grandes perdas, reiteraram o ataque a 11 de julho com redobrado vigor. Viram-se, porém, completamente derrotados e tomados de pânico debandaram, perseguidos pelos vencedores; brancos e índios, fiéis aos seus abarés, que com a maior serenidade tanto haviam cooperado na defesa da praça.

Foi então que Nóbrega e Anchieta se ofereceram como parlamentares junto aos tamoios, permanecendo na praia de Iperoig, como reféns durante meses, até que se estabelecesse a paz entre brancos e gentios.

Taunay (2016) também enfatiza a figura de Tibiriçá: “Tibiriçá que com inabalável firmeza recusara trair a causa dos seus caros missionários, viria a morrer naquele mesmo ano, no dia de Natal, muito chorado pelos jesuítas que o sepultaram no solo do sua igreja”.

Já a história de São Carlos do Pinhal, interior de São Paulo. Ela já nasce com nome de santo em homenagem a São Carlos Borromeu, padroeiro da família Botelho.

Do encontro das sesmarias do Pinhal, do Monjolinho e do Quilombo teria surgido o núcleo urbano. O primeiro a se preocupar com essa questão e doar terras foi Carlos José Botelho conhecido como Botelhão e dono da sesmaria do Pinhal. Seu filho, Antônio Carlos de Arruda Botelho, futuro Conde do Pinhal, se dedicou junto com seus irmãos erguer a cidade, (NEVES, 1994).

Segundo Neves (1994, p. 4) a cidade "Não nasceu do improviso, mas bem planejada". E continua:

A primeira tessitura viária foi igualmente traçada dentro dessa ampla visão. Quadras desafogadas de noventa metros de testada, orientada na direção norte-sul, deveria ocupar a colina central, não fora o impasse criado pelo proprietário da Sesmaria do Monjolinho, João Alves de Oliveira, que não permitiu a expansão do nascente povoado em direção ao norte.

A data de fundação ficou marcada como 4 de novembro de 1857 e se constituiu a partir da igreja matriz:

Ao todo eram apenas 7 quarteirões, onde viviam no máximo milhar de pessoas, porquanto o arrolamento de eleitores qualificados para votar, presidido pelo primeiro juiz de Paz, Paulino Carlos de Arruda Botelho, em 17 de janeiro de 1858, assinala a existência de 210 cidadãos aptos, dos quais 191 casados, 16 solteiros, 2 viúvos e 1 de estado civil ignorado. (NEVES, 1994, p. 4) 
A participação de Antônio Carlos de Arruda Botelho na construção da cidade não para aí. Fundou a Companhia do Rio Claro de Estradas de Ferro que ligava Rio Claro a Jaú, a Casa Comissária Arruda Botelho (Santos), o Banco de São Paulo, o Banco União de São Carlos e Banco de Piracicaba, a Companhia Agrícola (Ribeirão Preto). Além disso, foi vereador da Câmara de Araraquara, Juiz Municipal de Araraquara, Deputado Provincial e Senador pelo Estado de São Paulo. O sitio eletrônico da Casa do Pinhal² (2016) sintetiza:

Por seus feitos, especialmente a participação na Guerra do Paraguai e, posteriormente, a construção da Estrada de Ferro, adquiriu ao longo de sua vida os títulos de Coronel Comandante Superior da Guarda Nacional (1867), Oficial da Ordem da Rosa (1868), Barão do Pinhal (1879), Visconde do Pinhal (1883) e Conde do Pinhal (1887).

Assim o grande herói e benemérito da cidade foi o Conde do Pinhal. Completando a reverência, sua segunda esposa, Anna Carolina de Oliveira, condessa do Pinhal era conhecida pelo amor e zelo com que tratava os escravos da fazenda, cuidando ela mesma dos ferimentos e enfermidades deles ainda seguindo o sitio eletrônico da Casa do Pinhal (2016).

\section{NOME DE SANTO}

O planalto Piratininga passou a se chamar São Paulo em 25 de janeiro de 1554, conforme carta de José de Anchieta (1933, p. 38):

Assim, alguns dos irmãos mandados para esta aldeia, que se chama Piratininga, chegamos a 25 de Janeiro do Ano do Senhor de 1554 celebramos, em paupérrima e estreitíssima casinha, a primeira missa, no dia da conversão do Apóstolo São Paulo, e, por isso, a ele dedicamos nossa casa

E continua, descrevendo a situação:

De Janeiro até o presente tempo permanecemos, algumas vezes mais de vinte, em uma pobre casinha feita de barro e paus, coberta de palhas, tendo quatorze passos de comprimento e apenas dez de largura, onde estão ao mesmo tempo a escola, a enfermaria, o dormitório, o refeitório, a cozinha, a dispensa. Todavia, não invejamos as espaçosas habitações, de que gozam em outras partes os nossos Irmãos, pois N.S. Jesus Cristo se colocou em mais estreito lugar, e dignou-se nascer em pobre manjedoura entre dois brutos animais e morrer em altíssima cruz por nós, Os índios por si mesmos

\footnotetext{
${ }^{2}$ A antiga fazenda do Pinhal com seu casario foi restaurada (com algumas reformas) está aberto a visitações, eventos e ainda guarda um acervo pessoal da família.
} 
edificaram para nosso uso esta casa; mandamos agora fazer outra algum tanto maior, sujos arquitetos seremos nós, com o suor do nosso rosto e o auxílio dos índios (ANCHIETA, 1933, p. 43).

A data oficial de fundação da cidade é atualmente 25 de janeiro de 1554 por conta desta carta de Anchieta, que acabou sendo inclusive considerado um dos seus fundadores, ou o principal deles.

O Padre Viotti (1984, p. 130) reafirma a data, mas nela Anchieta aparece como o primeiro professor do colégio e não a pessoa que celebra a missa:

Mas o nome de São Paulo, que hoje individua a maior e mais próspera cidade do Brasil, foi dado a 25 de janeiro de 1554, à casa inaugurada em Piratininga pelos fundadores efetivos, por nesse dia, que foi o da chegada, terem celebrado aqui a missa da conversão de São Paulo. Celebrou-a Manuel de Paiva, superior dos doze ou treze jesuítas, para cá de São Vicente enviados pelo Padre Manuel da Nóbrega, vice-provincial e logo mais provincial do Brasil.

E essa casa era o Colégio, de que Anchieta foi o professor por então único, e o sustentáculo, durante dez anos seguidos.

Há mais de mil quilômetros dali e muitos anos depois, a figura de Anchieta aparece também dando o nome ao então povoado do Cricaré. No ano de 1596 (NARDOTTO, 2001) ou 1566 (JESUS, 2016). Apesar de ter dado o nome atual da cidade, não foi considerado o fundador da cidade e nem mesmo a data como a sua fundação, como aconteceu com São Paulo.

São Carlos do Pinhal, hoje somente São Carlos recebeu seu nome já na fundação segundo a história local. São Carlos Borromeu era o padroeiro da família Botelho a quem foi atribuída a fundação (BOTELHO FERRAZ, 1957).

\section{OS (QUASE) ESQUECIDOS}

João Ramalho, muito embora tenha sido considerado importante não só pelo estabelecimento do povoado, mas também pela sua defesa, inclusive no episódio mencionado, perde um pouco seu relevo frente à bravura de Tibiriçá. Quando da chegada dos jesuítas no local o mesmo já se encontrava vivendo serra acima, onde hoje está a cidade de Santo André. Ao que parece os jesuítas tiveram vários desacertos, "desinteligência” segundo Leite (1944, p. 14), pois ele teria adotado hábitos indígenas, andando nu e casado com várias mulheres, 
adotando inclusive nome indígena. Inverso, portanto de Tibiriçá, um indígena convertido ao cristianismo e que adotou um nome português. Não fosse a relevância para a historiografia oficial bandeirantista, que valorizou esta miscigenação cultural e talvez o nome de João Ramalho tivesse sido esquecido. A própria aliança com Tibiriçá só foi possível a partir de João Ramalho, seu genro.

Outra personagem relegado a segundo plano foi Leonardo Nunes. No lugar deste aparece a figura de José de Anchieta. Segundo Custódio e Hilsdorf (1995) em julho de 1553, Leonardo Nunes teria juntamente com o auxílio do "língua" Pero Correa, de outros Jesuítas e de 50 catecúmenos, fundado um aldeamento entre o Rio Tiete e o Tamanduateí. Na missa de 25 de janeiro de 1554 em que o Padre Anchieta participa, mas não a celebra, o aldeamento já estava feito. Até mesmo sua atuação como primeiro professor do colégio é questionada por Serafim Leite que diz ter sido Antonio Rodrigues o primeiro professor.

Em São Carlos, o primeiro quase esquecido foi Jesuíno de Arruda. Na comemoração do centenário da cidade foi o auge de uma polêmica que vinha desde o início do século. $\mathrm{O}$ nome de Jesuíno de Arruda aparecia como fundador da cidade de São Carlos, pois as terras doadas para a construção da igreja pertenciam a ele e não a família Botelho. Uma série de artigos e debates circularam nos jornais de época, cada grupo defendia seu "fundador". Até uma campanha para angariar fundos para erguer o túmulo de Jesuíno de Arrida aconteceu. No final o homenageado foi mesmo o Conde do Pinhal. Para marcar as posições, dois livros com as duas visões saíram desta discussão: Jesuíno de Arruda e a Fundação de São Carlos de Theodorico de Camargo (1957) e São Carlos e Sua Fundação de Maria Cecília Botelho Ferraz (1957).

São Carlos lidera em personagens esquecidos. Gregório e Pedro José Neto são outros que desaparecem da história.

O "picadão de Cuiabá" aberto após a descoberta de ouro em Mato Grosso seria marcante para a região conhecida como "sertões de Araraquara". Tropeiros, comboios de gado, aventureiros, "bandeirantes que a historiografia tradicional não tardou a tornar símbolo e arquétipo dos paulistas" (MORILA, 2005, p. 40) fizeram surgir pequenas pousadas e estalagens de quando em quando para descanso, alimentação das tropas e trocas ocasionais. Um destes pousos se localizava em São Carlos. Lá um posseiro de nome Gregório se instalava. O que se sabe sobre ele é pouco segundo Truzzi e Follis (2012). Como era usual no 
processo de ocupação do interior de São Paulo, esse e outros posseiros foram expulsos a mando dos sesmeiros.

Outro posseiro dos "sertões de Araraquara" teve seu nome registrado. Trata-se de Pedro José Neto, reconhecido oficialmente como fundador da cidade de Araraquara (da qual a Vila de São Carlos fazia parte). Esquecido na história de São Carlos ele é mais do que lembrado nas comemorações de Araraquara. Fugido da Inconfidência Mineira segundo Telarolli (2003) nadou rios caudalosos e percorreu sozinho os sertões apinhados de índios até se apossar de grandes quantidades de terras nos sertões de Araraquara. Para completar sua saga morreu vitimado de um coice de burro. Truzzi e Follis (2012) apontam para os exageros das narrativas e o mostram como simples morador da Vila com sua família. Em artigo recente Follis (2016, p.163) reconstitui sua história expondo o que chamou de "saga fantasiosa", "levada a sério e transformada em verdade pelos ufanistas de plantão"

Em São Mateus, o grande esquecido parece ter sido o Padre José de Anchieta. Ao contrário do que aconteceu com São Paulo. A data comemorativa é dia 21 de setembro de 1544, que marca o início da colonização portuguesa e não a data da missa realizada por Anchieta em 21 de setembro 1596. Segundo Ventorim (2016):

Os primeiros colonizadores portugueses chegaram à região de São Mateus por volta do ano 1544 .

Por este motivo, o local é considerado um marco na colonização do solo do Espírito Santo.

A cidade, edificada sem simetria e à pequena distância do rio, seguia os padrões urbanos das cidades portuguesas. A área situada próxima ao rio e ao porto tornou-se um centro aristocrático e o principal núcleo de atividades da população. Essa aristocracia local trouxe arquitetos portugueses que edificaram a maioria dos casarões do porto. Além disso, as ruas foram calçadas com pedras transportadas por navios e o cais do porto pôde ser protegido, facilitando a atracação dos mesmos.

Quanto a Anchieta, Nardoto e Lima (2001, p. 28) faz a seguinte consideração: "Na história do Padre José de Anchieta lê-se que, ao passar pelo rio Cricaré, em 1596, celebrou missa para alguns náufragos. Carece, no entanto, de documentação para tornar-se fato histórico."

Manteve-se o nome dado por Anchieta, o dia e o mês da missa, mas não o ano e nem mesmo Anchieta como fundador.

Não demora muito a perceber a ausência de negros na história oficial. São Mateus foi um entreposto importante de negros escravizados e até hoje mantém várias comunidades 
quilombolas. Uma das três sesmarias que compunham São Carlos tinha o nome de Sesmaria do Quilombo. Se o negro é ausente, o imigrante branco e em especial o italiano é marcante na historiografia de São Carlos, São Paulo e São Mateus. Mas a imigração é marcada como uma "segunda fundação", e foge do escopo deste trabalho.

\section{MITOS DE FUNDAÇÃO}

O que está por trás dos mitos de fundação? Por que em uma cidade se eleva a figura de um Jesuíta em detrimento de tantos outros sujeitos históricos? O que leva em outra cidade a fazer exatamente o contrário, deixando de lado Anchieta com o fundador? Por que a historia oficial silencia no caso de São Paulo e São Carlos a antiga ocupação e reafirma um marco como uma missa ou uma doação de terras? Por que em São Mateus se fez exatamente o contrário?

Não podemos, sem recair nos deslizes da historia oficial, querer responder de forma categórica estes questionamentos. Mas podemos levantar algumas hipóteses.

Devemos ressaltar que as datas de fundação são importantes para pensar algumas hipóteses. São Mateus e São Paulo foram fundadas no inicio da colonização portuguesa, já São Carlos foi fundada no século XIX, quando o Brasil já era independente.

Por esta razão o índio é elemento que aparece em São Paulo e São Mateus. Interessantemente o índio que povoa a história tradicional é mais um índio romântico do indianismo brasileiro do que um sujeito histórico. Os traços de bravura e destemor são ressaltados. No caso de São Mateus, os valentes Aimorés foram os primeiros a resistir, e ganhar dos invasores portugueses. No caso de São Paulo, lutando ao lado dos portugueses contra tribos em maior número que sitiavam sem aparente razão a pequena vila em que viviam em paz. Em São Mateus, as armas de fogo que denotavam a superioridade militar portuguesa, não foram o bastante para vencer a valentia dos nativos. Em São Paulo, as armas de fogo, pelo contrário, não demonstrava superioridade, segundo Taunay: "as armas de fogo de tiro muito lento e pequeno raio de alcance". A superioridade era o número. Mas com valentia e com a própria vida resistiu Tibiriçá.

Também os Jesuítas aparecem em São Mateus e em São Paulo, especialmente Anchieta. Nomeando cidades, rezando missas, inaugurando colégios. A presença deles é marcante na historiografia. Mais marcante ainda é a figura de Anchieta. Muito embora não 
tenha sido, como vimos, Anchieta aparece como fundador e primeiro professor do colégio de jesuítas de São Paulo. Se for para destacar um Jesuíta por que não o mais conhecido deles?

Mas em São Mateus ele quase que desaparece, mesmo que registrada em carta sua presença. Aqui a razão parece ser simples, a anterioridade. É mais interessante São Mateus ser uma das primeiras cidades do Brasil, "um marco na colonização do solo do Espírito Santo" (VENTORIM, 2016).

No caso de São Paulo, retroceder alguns meses (de janeiro de 1554 para julho de 1553) não fará diferença alguma na questão da anterioridade.

O momento era outro na fundação de São Carlos. A primeira pousada, os primeiros posseiros não são importantes, nem para ressaltar uma anterioridade da cidade. $O$ mais importante aqui é a figura do empreendedor, o planejador. A família Arruda Botelho, e mais especificamente o Conde do Pinhal é a figura exaltada. Sesmeiro, fazendeiro de café tornado nobre, empreendedor e planejador moderno, benemérito, pai, esposo, herói de guerra. É um o que se espera de um membro da elite paulista. Não haveria figura melhor para colocar como fundador. Até o Padroeiro italiano denota uma superioridade, um padrão europeu, tanto cobiçado e representativo no século XIX. Neste sentido a presença ou não de Jesuíno de Arruda é uma falsa questão. Outro membro da elite.

O posseiro que lutou contra os índios para se estabelecer, o tropeiro que fundou uma pousada, o negro que fundou um quilombo são menos importantes, mesmo que estes denotem a anterioridade da cidade. Aqui o que importa não é a anterioridade, nem a valentia ou bravura, mas a civilização moderna. Não é sem razão que São Carlos se orgulha de ser uma das primeiras a ter luz elétrica e telefone e hoje autointitulada capital da tecnologia.

É interessante lembrar de João Ramalho e Pedro José Neto. O interessante aqui não é o mito em si, mas o fato de que eles entram no "rol das exceções, visto que, em regra as cidades atribuem ao proprietário de terras doadas à Igreja o título de fundador, quase sempre um grande fazendeiro pertencente à classe dominante.” (TRUZZI; FOLLIS, 2012, p.31) Exceção por certo, mas não injustificada. Se pensarmos na historiografia apologética do bandeirantismo, os mitos envolvendo a figura de Pedro José Neto o enquadram nesta categoria. De maneira semelhante, João Ramalho pode ser incluído nos fundadores/defensores da cidade de São Paulo.

Pedro José Neto também se aproxima de Tibiriçá. Ambos se aventuraram para além do seu próprio universo, o primeiro geograficamente e o segundo ideologicamente. Ambos 
sofreram uma morte trágica nesta aventura. Defendendo-se de índios ou das adversidades mostram ideais de lealdade, bravura, honra e destemor.

\section{A HISTORIOGRAFIA LOCAL: ENTRE CRÔNICA E HISTORIA}

Os títulos dos livros que ajudam a construir a historiografia oficial da cidade são sugestivos: A história de São Paulo de Aureliano Leite, História de São Mateus de Eliezer Nardoto e Herinéia Lima, História da Cidade de São Paulo de Taunay, São Carlos e sua fundação de Maria Cecilia Botelho Ferraz. A "história de" sugere que toda a história está contida entre as capas do livro. Isso ajuda a dar credibilidade e perpetuar os mitos contidos nestas obras.

São "tradições inventadas" que como aponta Hobsbawn (2012. p. 12) "visam inculcar certos valores e normas de comportamento através da repetição, o que implica, automaticamente; uma continuidade em relação ao passado". Assim é interessante buscar os valores e normas que se quer inculcar nos mitos de fundação como se tentou fazer neste artigo, lembrando há muitos mitos nas histórias oficiais além da própria fundação da cidade.

Mas e se quisermos achar outros sujeitos históricos que participaram da história da cidade? Como encontrar o sujeito comum? Onde encontrar "Quem construiu Tebas, a das sete portas?" como sugeriu Bertolt Brecht no poema Perguntas de um Operário Letrado?

Felizmente parece haver na berlinda da "História de" uma série de cronistas que não almejam (ou não conseguem alcançar) o status de historiador local. Suas histórias são consideradas por vezes fantasiosas, mas sempre menores em relação à "história de" e seus heróis. São pessoas que se destacaram pelo peculiar, são casos curiosos e interessantes, são histórias orais que as avós contavam, enfim crônicas do dia-a-dia da cidade. Assim, em São Mateus temos Aguiar (1995) que narra diversas histórias recolhidas oralmente. Nela desfiam escravos fugidos, amores proibidos, prostitutas, trabalhadores artesanais junto com assombrações. No Caso de São Carlos Nicola Gonçalves (s/d) em Crônicas e Histórias de São Carlos e outras localidades. Em São Paulo, Ernani da Silva Bruno (1954) em História e tradições da cidade de São Paulo e Affonso de Freitas (1985) em Tradições e reminiscências paulistanas entre outros. Diversamente dos historiadores oficiais, estes cronistas tendem a ser em maior número. Ao lado destes cronistas, alguns memorialistas podem se somar, como Jacob Penteado (1962) em São Paulo. 


\section{CONSIDERAÇÕES FINAIS}

Tomado o recorte temporal deste artigo, percebemos que os mitos de fundação parecem ganhar relevância não só na historiografia da cidade, mas também nos sítios da internet, nos panfletos turísticos e nas comemorações oficiais, o que seria um interessante objeto de pesquisa.

Mas não são os únicos. Na construção da história das cidades vão se somando heróis individuais ou em grupo, simbolizando o que a elite pretende como ideal. Assim imigrantes europeus, notadamente os italianos nas três cidades são supervalorizados como elementos civilizatórios e de cultura. A educação também constrói seus heróis como analisado por Morila (2004) para São Paulo e Jesus (2016) para São Mateus. Na cultura, nas artes, na política seguem-se mitos construídos e repetidos.

Truzzi e Follis (2012, p.31) apontam para a perpetuação destes mitos, quando analisam o caso de Pedro José Neto:

Apesar disso, não foram poucos os que abordaram a "história" de Pedro José Neto, um dos primeiros posseiros a se instalar nos Sertões de Araraquara e cometeram vários equívocos. Alguns, pelo intuito de transformar Pedro Jose Neto num mito, uma espécie de herói da região ou, pelo menos, da cidade de Araraquara. Outros, simplesmente por repetir e, em alguns casos, até mesmo incrementar, sem maiores preocupações e questionamentos, a versão atribuída pelos primeiros.

Conforme nos ensina Hobsbawm (2012), os historiadores estão envolvidos no processo "contribuem, conscientemente ou não para a criação, demolição e reestruturação de imagens do passado [...]". Não podemos considerar, portanto como simplesmente equívocos ou meras repetições.

\section{REFERÊNCIAS BIBLIOGRÁFICAS}

AGUIAR, M. de. Constância d'Angola: a eterna luta das mães negras. São Mateus: BrasilCultura, 1995.

ANCHIETA, J. de. Cartas, informações, fragmentos históricos e sermões. Rio de Janeiro: Civilização Brasileira, 1933.

ARRUDA, José Jobson \& TENGARRINHA, José Manuel. Historiografia Luso-Brasileira Contemporânea. Bauru, EDUSC, 1999. 
BOTELHO FERRAZ, M. C. São Carlos e Sua Fundação. São Carlos: Cupolo, 1957.

BRUNO, E. S. História e tradições da cidade de São Paulo: metrópole do café (1872-1918); São Paulo de agora (1918-1954). 2a ed. Rio de Janeiro: José Olympio, 1954.

CAMARGO, T. Jesuíno de Arruda e a fundação de São Carlos: supremacia dos documentos. São Paulo: Ed. Revistas dos Tribunais, 1957.

Casa do Pinhal. Disponível em: http://www.casadopinhal.com.br/historia acesso em 22 de junho de 2016.

FERREIRA, A. B. de H. Miniaurélio Eletrônico versão 5.12. Curitiba: Positivo, 2004.

FOLLIS, F. Mito e história de um posseiro do Brasil Colonial nos Sertões de Araraquara. Revista de História Regional 21(1): 148-169, 2016.

FREITAS, A. de. Tradições e reminiscências paulistanas. São Paulo, Itatiaia, 1985.

GONÇALVES, N. Crônicas e Histórias de São Carlos e outras localidades. São Carlos: s/i, s/d.

HOBSBAWN. E. Introdução. In: HOBSBAWN. E; Ranger, T. A invenção das tradições. Rio de Janeiro: Nova Fronteira, 2012.

JAEGER, W. W. Paidéia: a formação do homem grego. $3^{\mathrm{a}}$ ed. São Paulo: Martins Fontes, 1994.

JESUS, R. M. Mal-estar na educação infantil no município de São Mateus, ES: Resgate histórico. (Exame de qualificação). Programa de Pós-graduação em Ensino na Educação Básica - UFES. São Mateus, 2016.

MORILA, A. P. Dando o tom: música e cultura nas ruas, salões e escolas da cidade de São Paulo (1870-1906). Tese (Doutorado em Educação) - FEUSP, São Paulo. 2004.

MORILA, A. P. Um monumento na avenida: a Escola Normal de São Carlos. Revista HISTEDBR On-line, v.19, p. 40-62, 2005.

NARDOTO, E; LIMA, H. História de São Mateus. 2a ed. São Mateus: Atlântica, 2001.

PENTEADO, Jacob. Belenzinho, 1910: retrato de uma época. São Paulo: Martins, 1962.

TAUnAY, A. d'E. Taunay. História da Cidade de São Paulo (1953). Disponível em http://www.literaturabrasileira.ufsc.br/_documents/0006-01759.html acesso em 28/04/2016.

TELAROLLI, R. Para uma história de Araraquara: 1800 a 2000. Araraquara: Laboratório Editorial, 2003.

TRUZZI, O; FOLLIS, F. A ocupação dos sertões de Araraquara: das Sesmarias e 
Fronteiras: Revista de História

Mitos de fundação de três cidades brasileiras: três santos, dois massacres e um coice de burro Ailton Pereira Morila

apossamentos à Lei de terras de 1850. São Carlos: Edufscar, 2012.

VENTORIM, L. Resoluções reforçam mecanismos de preservação de Sítios Históricos do Estado. Disponível em http://www.es.gov.br/Noticias/115918/detalhes.htm. Acesso em 28/07/2016.

VIOTTI, H. A. Cartas, correspondência ativa e passiva. São Paulo: Edições Loyola, 1984.

Recebido em: 10/05/2018 Aprovado em: 23/06/2018 